\title{
Identificação das demandas funcionais dos usuários de serviços públicos de reabilitação: sistematizando o acolhimento
}

Jane Fonseca Dias, Mariana Angélica Peixoto de Souza, Sheyla Rossana Cavalcanti Furtado, Marisa Cotta Mancini, Rosana Ferreira Sampaio

\section{Resumo}

Desde as últimas décadas o Brasil vivencia o aumento das doenças crônicas e da expectativa de vida que, associadas à crescente urbanização e industrialização, modificam o perfil de adoecimento da população, marcado por incapacidades transitórias/permanentes. Tais mudanças aumentam a demanda por serviços públicos de reabilitação e geram a necessidade de ampliar e diversificar tais serviços e constituí-los em rede integrada e efetiva. $\mathrm{O}$ adequado funcionamento e planejamento da rede de reabilitação dependem de dados que reflitam as condições funcionais dos usuários. Assim, um protocolo sistematizado, que possibilite o levantamento e qualificação das demandas funcionais desde o acolhimento do usuário, tem grande potencial para melhorar o direcionamento do caso entre os diversos profissionais e serviços da rede - Atenção Básica e Especializada. O objetivo deste estudo foi, através deste protocolo único, traçar o perfil dos usuários da rede pública de reabilitação de Belo Horizonte - MG. O protocolo foi aplicado no acolhimento de usuários da rede pública de reabilitação da cidade. No protocolo há questões que representam componentes da Classificação Internacional de Funcionalidade, Incapacidade e Saúde, para caracterização social, da saúde e funcional dos usuários. Para descrição funcional há 25 questões alocadas em 10 domínios: Mobilidade, Comunicação, Eutrofia, Auto-cuidado, Dor, Atividade Interpessoal, Energia e Sono, Afeto, Tarefas e Demandas Gerais, Trabalho Remunerado. Foram avaliados 516 usuários, média de idade 57 anos, 75\% mulheres, 47\% casados/união estável, média de 3 filhos. Quanto à escolaridade, $65 \%$ concluíram até o ensino fundamental. Menos da metade trabalhava $(41 \%)$ e $35 \%$ eram aposentados. Sedentarismo (65\%) e sobrepeso (31\%) foram os principais fatores de risco. Na autoavaliação de saúde, $34 \%$ avaliaram como boa/muito boa a saúde física e $43 \%$ a emocional; $32 \%$ precisavam de ajuda nas atividades diárias e $75 \%$ realizavam algum tratamento de saúde. Na descrição funcional, $87 \%$ relataram dificuldade grave/completa em pelo menos um domínio, sendo Dor o mais frequente (58\%). A mediana do escore funcional foi 23,89 (escala de 0 a 100). A maioria iniciou a reabilitação na atenção básica $(n=398)$ e em média apresentava dificuldade grave/completa em 5 itens da descrição funcional comparado com média de 8 itens para os que iniciaram na atenção especializada $(n=109)$. Nove usuários receberam apenas orientações. Espera-se que o uso do protocolo contribua para a redução da fila de espera para atendimento de reabilitação, assim como redução dos encaminhamentos inadequados entre os serviços.

Descritores: Reabilitação; Acolhimento; Classificação Internacional de Funcionalidade; Incapacidade e Saúde 